\title{
Sustained Effects of the PATHS Curriculum on the Social and Psychological Adjustment of Children in Special Education
}

\author{
Chi-Ming Kam, Mark T. Greenberg, and Carol A. Kusché
}

Compared to students in general education, students in special education classrooms have a higher risk of developing emotional and interpersonal problems. Special education students have to deal with the frustrations they experience that accompany their learning difficulties (Grande, 1988; Keilitz \& Dunivant, 1987). Quite often, these children also suffer from compromised mental or physical health conditions that can disrupt their school learning and social relationships (Gallico, Burns, \& Grob, 1988; Myers \& Hammill, 1990). Many special education students lack the skills to negotiate positive relationships in school (Bryan, 1991, 1997; Kavale \& Forness, 1996; La Greca \& Vaughn, 1992; Landau \& Moore, 1991). Moreover, compared to students in general education, students with special needs also engage more often in problem behaviors that may disrupt their relationships with peers and teachers (Chapman, 1988; Dudley-Marling \& Edmiaston, 1985; Pearl, 1987, 1992; Schumaker \& Hazel, 1988). Within integrated classrooms, students with special needs are more likely to be nominated by their nondisabled peers for aggressiveness and disruptiveness, and they are also more likely to be

$\mathrm{n}$ this study, the authors examined the long-term effectiveness of the PATHS (Promoting Alternative THinking Strategies) curriculum on the adjustment of school-age children with special needs. The

PATHS curriculum focuses on promoting children's emotional development, self-regulation, and social problem-solving skills. Eighteen special education classrooms were randomly assigned to treatment and control conditions in this controlled trial. Teachers received both training and ongoing consultation and provided PATHS to students in Grades I through 3. Data were collected before the intervention and for 3 successive years. Growth curve analysis indicated that the intervention reduced the rate of growth of teacher-reported internalizing and externalizing behaviors 2 years after the intervention and produced a sustained reduction in depressive symptoms reported by the children. Discussion focuses on the need for social-emotional learning (SEL) programs in special education and factors that can promote SEL among children with special needs.

rejected by their schoolmates (Farmer, 2000; Farmer \& Hollowell, 1994). Studies have also shown that students with learning disabilities are at a greater risk for depression and suicide (Bender, Rosenkrans, \& Crane, 1999; Bender \& Wall, 1994; Huntington \& Bender, 1993; McBride \& Seigel, 1997).

Despite the fact that some kind of social skills training or behavior management program for addressing children's deficits in social competence are usually implemented in special education, many of these practices have not been adequately evaluated and supported by evidence. Within special education, there is a pressing need for the implementation of evidence-based preventive interventions to reduce children's risk of developing maladaptive behaviors and enhance children's social and emotional competence. Recently, special educators have called for a new agenda of prevention within special education (Farmer, Quinn, Hussey, \& Holahan, 2001; Forness et al., 2000; Kamps, Kravits, Stolze, \& Swaggart, 1999; Kauffman, 1999a; Walker et al., 1998). Others have called on school psychologists and special educators to make better use of evidence-supported prevention/intervention (Carnine, 1997; Kratochwill \& Stoiber, 2000; Simpson, 1999; Stoiber \& Kratochwill, 2000). In particular, some leaders in the field have suggested that 
special educators should embrace primary and secondary prevention, which, when effectively implemented, can reduce the need for tertiary prevention and other forms of costly treatments for special education students (see Farmer et al., 2001; Forness et al., 2000; Kauffman, 1999b). The present study examines the sustained outcomes of a comprehensive socialemotional learning program (Providing Alternative THinking Strategies, or PATHS; Kusché \& Greenberg, 1994) on the social and behavioral adjustment of children with special needs.

As indicated in recent reviews (Durlak, 1995; Durlak \& Wells, 1997; Weissberg \& Greenberg, 1998), most universal schoolbased prevention programs have tended to (a) be piecemeal in nature, (b) focus primarily on one specific developmental domain, (c) be of short duration, (d) utilize outcome measures of unknown or inadequate reliability and validity, and-with very few exceptions-(e) be based on vague models of development and change. As a result, few comprehensive evaluations of such programs have been conducted (Greenberg, Domitrovich, \& Bumbarger, 2001), and of these, few have demonstrated maintenance and generalization of effects. This is surprising, given the wide range of curricula intended to promote social competence and prevent disorders that are used in elementary education (Payton et al., 2000).

Research has indicated that comprehensive prevention programming in the classroom setting has the potential to provide much-needed assistance for children without disabilities and children who are at risk for behavioral problems. Furthermore, recent critiques of current practices have indicated that there are a number of significant changes in current curriculum, implementation, and research that might lead to improved outcomes (Durlak, 1995; Greenberg et al., 2001; Institute of Medicine, 1994; Weissberg \& Elias, 1993; Weissberg \& Greenberg, 1998). Seven of the most important factors are as follows:

1. utilizing a program of longer duration,

2. synthesizing a number of successful approaches,
3. incorporating a developmental model,

4. providing greater focus on the role of emotions and emotional development,

5. providing increased emphasis on generalization techniques,

6. providing ongoing training and support for implementation, and

7. utilizing multiple measures and follow-ups for assessing program effectiveness.

Based on these factors, PATHS was designed as a comprehensive curriculum including critical factors that previously had been underemphasized.

The PATHS curriculum model draws on basic developmental research suggesting that the development of more complex and accurate plans and strategies (socialcognitions) regarding interpersonal problems has a major influence on children's social behavior. For example, the ability to think through problem situations and to anticipate their occurrence is critical for socially competent behavior (Dewey, 1933; Dodge, 1986; Spivak \& Shure, 1974). However, these "cold" cognitive processes are likely to be effectively used in real-world conditions (e.g., when being teased) only if children can both accurately process the emotional content of the situation and effectively regulate their emotional arousal so that they can think through the problem (Pellegrini \& Urbain, 1985). If children misidentify their own feelings or those of others, they are likely to generate maladaptive solutions to a problem. In addition, the child's motivation for communicating his or her feelings and problem solving in interpersonal contexts will also be greatly affected by the modeling and reinforcement of adults and peers. Although emotional awareness, understanding, and regulation are implicit in models that have been developed to promote social competence (Elias \& Clabby, 1989; Kendall \& Braswell, 1985; Shure \& Spivak, 1988; Urbain \& Savage, 1989), they have rarely been a central focus of preventive intervention.

Thus, emotional understanding and emotional regulation appear to be important aspects of social competence and an appropriate target for prevention trials for both typical children and children who are behaviorally at risk. In this article, we present the outcomes of the PATHS curriculum when it is implemented in special education settings. PATHS focuses on building emotional awareness and emotional regulation skills in early school years and integrating the skills in selfcontrol with social problem-solving skills. PATHS takes a classroom-wide approach, and the curriculum is intertwined with the existing curriculum in the school. Although the curriculum teaches individual skills and competence, it also promotes a change in classroom atmosphere to increase empathy and openness in dealing with emotional needs.

\section{THE PATHS CURRICULUM}

\section{The ABCD Model}

The PATHS preventive intervention program is based on the ABCD (affectivebehavioral-cognitive-dynamic) model of development (Greenberg \& Kusché, 1993; Greenberg, Kusché, \& Speltz, 1990), which places primary importance on the developmental integration of affect (and emotion language), behavior, and cognitive understanding as they relate to social and emotional competence. A basic premise is that a child's coping, as reflected in his or her behavior and internal regulation, is a function of emotional awareness, affective-cognitive control and behavioral skills, and social-cognitive understanding. Implicit in the ABCD model is the idea that during the maturational process, emotional development precedes most forms of cognition. As a result, in early life, affective development is an important precursor of other modes of thinking and later needs to be integrated with cognitive and linguistic functions. Furthermore, a critical developmental achievement occurs when the child begins to regulate internal affective states through verbal self-regulation (Katan, 1961; Kopp, 1982; Luria, 1980; Meichenbaum, 1977; Pine, 1985; Vygotsky, 1978).

Between the ages of 5 and 10 years, children undergo a major developmental 
transformation that generally includes increases in cognitive-processing skills (Kendler, 1963; White, 1965). This transition, and the accompanying changes, allow children to undertake major changes in responsibilities, independence, and social roles. During the elementary school years, further developmental integrations among affect, behavior, and cognition/ language occur. Thus, the relationships among these three components are crucially important to socially competent action and healthy development (Weissberg \& Elias, 1993). Taking this into account, the PATHS curriculum model synthesizes the domains of self-control, emotional awareness and understanding, and social problem solving to increase social and emotional competence.

\section{Four Assumptions}

The PATHS prevention strategy operates under the following four assumptions:

1. Children's ability to understand and discuss emotions is related to both communicative development and the ability to inhibit behavior and show self-control.

2. Children's ability to manage, understand, and discuss emotions operates under developmental constraints (Saarni \& Harris, 1989) and is also affected by socialization practices (Gordon, 1989; Malatesta, 1990).

3. Children's ability to understand their own and others' emotions is a central component of effective problem solving.

4. The school environment is a fundamental ecology, and one that can be a central locus of change.

As a result, PATHS was designed to be delivered by teachers with support from project staff, to be taught on a regular basis throughout most of the school year, and to provide daily activities for promoting generalization. Furthermore, we hypothesized that PATHS would increase protective factors (e.g., emotional understanding, social problem-solving skills) that avert maladjustment and decrease risk factors directly related to maladjustment.

\section{Effectiveness}

A number of randomized clinical trials have shown the short-term effectiveness of the PATHS curriculum. Using the same sample reported on herein (but also including children in general education classrooms), Greenberg, Kusché, Cook, and Quamma (1995) reported that the PATHS intervention led to significant improvements in the understanding of emotions, fluency in discussing emotions, and perceived efficacy in managing emotions. Moreover, in a large, randomized trial involving 48 schools in four U.S. communities (Conduct Problems Prevention Research Group, 1999), PATHS was used as the universal prevention model of the Fast Track Program. Initiated at the beginning of first grade, results after 6 months (spring of first grade) indicated (a) significant effects on child aggressive and disruptive behavior according to peer sociometric reports, and (b) improved quality of classroom atmosphere, based on ratings by independent observers. Further findings at the end of the third and fourth grades indicated continued reductions in the numbers of nominations of aggressive behavior by boys according to peer sociometric reports (Greenberg, Kam, Heinrichs, \& Conduct Problems Prevention Research Group, 2003). Reports of the efficacy of the PATHS curriculum have also involved students with special needs (Greenberg \& Kusché, 1998; Hindley \& Reed, 1999).

In the present study, we examined the long-term effectiveness of PATHS with children who had been identified with special needs. We examined the trajectories of students' outcomes across intervention and follow-up years. We hypothesized that on average, students receiving PATHS would have decreasing, stabilizing, or more slowly increasing trends in problem behaviors and depression in comparison to the control group. We further hypothesized that PATHS students would show a greater and faster gain in social competence than students in the control group.

\section{Method}

\section{Participants}

The sample consisted of 133 students with disabilities (97 boys, 36 girls; 88 White, 27 African American, 18 of other ethnic origins) studying in seven elementary schools in the Seattle, Highline, and Shoreline school districts. All students in our sample remained in their respective intervention or comparison schools throughout the 1-year intervention and were available for pre-, post-, and followup testing. The average age of these children when they first entered the study was 8 years 8 months (ranging from first grade to third grade). According to the classification system used by the state of Washington, 53 of these children had learning disabilities, 23 had mild mental retardation, 31 had emotional and behavioral disorders, 21 had physical disabilities or health impairments (many of these children had attention-deficit/hyperactivity disorder), and 5 had multiple handicaps. Students were primarily educated in selfcontained classrooms with a variable amount of mainstreaming. The classrooms were mixed-age (first to third grades), and each contained children with a variety of disability classifications.

\section{Curriculum Model}

This project used a pilot version of the PATHS curriculum. This 60-lesson version was adapted specifically as a model for the second and third grades and was composed of units on self-control, emotions, and problem solving. Special education classroom teachers used a modified version that placed a greater focus on teaching and reinforcing behavioral selfcontrol and less emphasis on the more advanced steps of problem solving.

The Self-Control Unit (Turtle). The Readiness and Self-Control Unit was developed for use in primary special education classrooms (as well as all preschool and kindergarten contexts). Its focus is teaching and reinforcing behavioral selfcontrol through the use of the Turtle Tech- 
nique (Schneider \& Robin, 1978), which consists of a series of structured lessons accompanied by a reinforcement program that each teacher tailors to his or her classroom needs. Through a series of lessons, children are told a metaphorical story about a young turtle who has both interpersonal and academic difficulties that arise because she or he does "not stop to think." With the assistance of a wise old turtle, the young turtle learns to develop better self-control (which involves going into his or her shell). Children practice "doing turtle" by folding their arms and following three simple steps for calming down, followed up by a discussion with the teacher of the problem and feelings. The goals for this unit are to increase selfcontrol, improve the group process, and increase attention.

During this unit, the teacher initiates a short-term reinforcement system that provides both social praise and symbolic material reinforcement ("turtle stamps") for correctly doing turtle whenever the children have a problem during the day. For approximately 3 weeks, the children receive material or social reinforcements when they use this response; during this time, the Turtle Technique is gradually shaped for use in appropriate contexts only. After the first 2 or 3 weeks, the material reinforcement (turtle stamp) is gradually faded from a continual schedule to an intermittent schedule and finally to a secondary back-up reinforcer system (e.g., participation in a lottery). The use of the reinforcement system and its fading was individualized to each class, and flexibility was encouraged, in consultation with the PATHS coordinator. Some teachers maintained either the intermittent reinforcement for longer periods or integrated this model as a system for reinforcing positive behavior in their classroom. As the curriculum continues, teachers encourage children to use the Turtle Technique as one way to stop and think. Teachers receive instruction in the use of labeled praise and effective verbal attributions for supporting children's maintenance of selfcontrol (Kusché \& Greenberg, 1994). The time needed to complete the Turtle Unit varies, depending on the developmental level of the students; the average time for completion in this study was about 5 to 7 weeks.

The Feelings Unit. The Feelings and Relationships Unit contains 35 lessons and focuses on teaching emotional and interpersonal understanding. The lessons cover approximately 35 different affective states and are taught in a developmental hierarchy, beginning with basic emotions (e.g., happy, sad, angry) and proceeding to more complex emotional states (e.g., jealous, guilty, proud). The Feelings Unit is based on an explicit model of emotional socialization and teaches children that it is okay to experience all of these feelings and that some feel comfortable and some feel uncomfortable. All behaviors, on the other hand, are not okay. In other words, children are taught to judge or evaluate behaviors rather than feelings. The children are also taught that feelings are signals that communicate useful information. If they learn to listen to what their feelings are telling them, they can use that information in making decisions about what to do next.

Because the ability to label emotional states is a central focus of the $\mathrm{ABCD}$ model (see chapter 4 of Greenberg \& Kusché, 1993), major emphasis is placed on encouraging such labeling for the facilitation of effective self-control and as a precursor to optimal problem resolution. The unit also includes instruction on such issues as cues for recognition of feelings in one's self and in others, effective selfmonitoring techniques, issues in managing feelings (i.e., making decisions regarding contextual issues in showing one's feelings vs. keeping them private), and empathic realization of how one's behavior can affect other people.

The Feelings Unit contains two explicit techniques for generalization. The first is the use of "Feeling Faces." During the first Feeling lesson, the children make their own "Feeling Boxes." After each emotion concept is introduced during subsequent lessons, the children personalize their own Feeling Faces for that affect. As the lessons progress, the children's boxes, which they keep in their desks, become full of different Feeling Faces. The Feeling Faces fit into an attached strip on the child's desk that reads, "I feel . ..." These strips and faces allow the children to communicate their feelings with minimal difficulty throughout the day, and they facilitate the children's understanding of how feelings change (i.e., children can physically "change" their Feeling Faces in a concrete manner when they become aware of a change in their internal emotional state). Teachers have their own set of Feeling Faces and use them as models for their students. Teachers are encouraged to promote generalization at the beginning and end of the school day, after recesses, and after lunchtime by suggesting that the children evaluate how they feel and display the appropriate face(s).

The development of self-control, affective awareness and communication, and beginning problem-solving skills are integrated during the Feelings Unit with the introduction of the Control Signals Poster (CSP). The CSP is modeled on the notion of a traffic signal and is a modified version of the stoplight used in The YaleNew Haven Middle School Social Problem Solving Program (Weissberg, Caplan, \& Bennetto, 1988). The CSP has a red light to signal "stop—calm down," a yellow light for "go slow-think," a green light to signal "go-try my plan," and at the bottom, the words "Evaluate-How Did My Plan Work?" In a series of lessons, the children are taught skills to use with the different signals of the poster and thus are introduced to a simplified, active model of problem solving. For purposes of generalization, a copy of the CSP is placed in the classroom, and teachers are coached on how to use this model for active problem solving during the school day.

Problem-Solving Unit. In addition, in this study a portion of the ProblemSolving Unit was taught to the children with special needs. Following the conceptual model originally developed by D'Zurilla and Goldfried (1971), Shure and Spivak (1978), and Weissberg et al. (1981), these lessons focused on identifying problems, identifying feelings, generating alternative solutions, evaluating consequences, and selecting the "best" plan. These lessons promoted improved 
cognitive skills and were integrated with the use of the CSP throughout the day.

Two main generalization techniques are used in the Problem-Solving Unit. First, the teacher keeps a "problem box" or "mailbox" on his or her desk or at some other central location. During the day, students who are experiencing a problem can write it down and place the note in the box. Once or twice each week, these real problems are used as the content for problemsolving meetings. In addition, teachers are encouraged to use peer conflicts or other interpersonal dilemmas as grist for active problem solving with individual children. An additional type of generalization that has increasingly been fostered as the curriculum has continued involves the transfer of problem-solving skills to other learning domains. Although PATHS focuses on the development of social thinking skills, we encouraged the teachers to use the problem-solving model when teaching other academic subjects (e.g., reading, mathematics, social studies). The degree to which teachers generalized problem solving throughout the day was assessed through use of the PATHS Consultant Rating Form (CRF). As teachers in special needs classrooms placed a greater focus on behavioral self-control and the Feelings Unit, most children in these classrooms completed only a small number of the problem-solving lessons during this 1-year trial; the teachers also commented that some problem-solving lessons were too developmentally advanced for their children.

Teacher Training. The intervention teachers attended a 3-day training workshop. The PATHS lessons were taught approximately three times per week, with each lesson lasting 20 to 30 minutes. Teachers began to teach the lessons in early October and finished in early April. Project staff observed and consulted with the teachers weekly. Other consultants were teachers and counselors with previous experience in working with special needs populations. These consultations were intended to enhance the quality of implementation through modeling, coaching, and providing ongoing feedback regarding program delivery. Each week, these teacher-consultants filled out the CRF, which contained seven items:

1. the teacher's understanding of the curriculum,

2. classroom management during the lessons,

3. teacher's use of the concepts outside the lesson,

4. teacher's attitude toward the curriculum,

5. teacher's openness to consultation,

6. the students' understanding of concepts being taught, and

7. students' participation during lessons.

The scale for all seven items in the CRF ranged from 1 (has considerable difficulty) to 5 (does very well). Most teachers were rated 3 or above, meaning that they were doing an "adequate or better" job in using the curriculum. During the first year of the intervention, the CRF was used in five special education classrooms and 16 general education classrooms. Weekly CRF scores over 24 weeks were averaged and correlated with students' outcomes. The correlations between the mean CRF scores and the change scores for students' outcomes ranged from 0.34 to 0.40 (probability values ranged from 0.05 to 0.09 ; Cheney, Greenberg, \& Kusché, 1991).

\section{Measures}

Because in this article we are focusing on the long-term effects of PATHS, we report here only the analyses on school adjustment outcomes that were measured at least three times (i.e., the preintervention/ postintervention measurement, plus some of the follow-up years).

Feelings Vocabulary. The Kusché Affective Interview (KAI; Kusché, Greenberg, \& Beilke, 1988) was used to assess children's understanding of emotions and their ability to provide examples of personal experience with different emotions. In this study, the size of the feelings vocabularies for the treatment and control groups was compared. Students were asked to "Name all of the different feelings you can think of." Nonfeelings word responses (e.g., "like throwing up," "hungry," "you like to play") were not included in the summary counts. The total number of positive feelings words and negative feelings words a child could cite were the two outcomes under investigation. A previous report of the effectiveness of PATHS indicated significant intervention effects for children with special needs on other measures of children's emotional understanding at posttest (Greenberg et al., 1995).

Social Problem-Solving Skills. The Social Problem-Solving Interview (SPSI; Greenberg \& Kusché, 1988) was used to assess the children's social thinking skills through three different hypothetical vignettes depicting being teased, being rejected from a group, and having an object taken away by a peer. Each story was read aloud to the child, and a corresponding illustration was presented. The children were asked what they thought would happen next in the story, whether they thought they could solve the problem, and what they would do or say in such a situation. A summary score was created that reflected both the number and effectiveness of strategies generated across the three stories. Each alternative response given by a child was coded for its level of effectiveness (e.g., prosocial and direct discussion $=3$, nonconfrontational and avoidant $=2$, aggressive $=1$ ). Scores for each alternative were then summed within each of the three stories and across stories to produce a total effectiveness score (range $=3-9)$. Coder reliability, which was assessed for $20 \%$ of the interviews, was .86 for the total effectiveness score.

Child Self-Report of Depression. Children's self-ratings of depressive symptomatology were obtained via the Children's Depression Inventory (CDI; Kovacs, 1983, 1992). The CDI is a 27-item self-report measure of depression. Each of the items consists of three statements. For each item, the child was asked to describe his or her feelings during the past 2 weeks. The reported reliability of the CDI scale ranges from 0.71 to 0.89 (Kovacs, 1992). Both a total score and scores for five subscales are provided. In our study, 
the total CDI score was used to measure each child's overall level of depression.

Teacher Ratings of Problem Behavior. The Child Behavior ChecklistTeacher Report Form (CBCL-TRF; Achenbach, 1991) was used to assess children's internalizing and externalizing symptomology, as well as the children's adaptive functioning in school. The CBCL-TRF contains a 118-item checklist of behavioral and emotional problems commonly seen by teachers. Responses to the checklist yield eight narrow-band scores and two broad-band scores: Internalizing and Externalizing. Separate norms are given for boys and girls ages 6 to 11. A $T$ score of 60 represents 1 standard deviation from the norm, and a $T$ score of 70 represents 2 standard deviations from the norm.

Teacher Ratings of Social Competence. To assess school-related social and emotional competence, we used the Social Competence subscales of the Teacher-Child Rating Scale (TCRS; Hightower et al., 1986). The TCRS is a 20-item, 5-point rating scale for teachers. It yields four reliable factors: Frustration Tolerance, Assertive Social Skills, Task Orientation, and Peer Sociability. The TCRS has demonstrated adequate testretest reliability, and its factors have shown high internal validity (.85-.95). Higher scores on all factors are indicative of more adaptive functioning.

\section{Evaluation Design}

The study was a randomized intervention trial in which special education classrooms were assigned to intervention or control conditions. A presentation was made to interested special needs teachers in the seven schools. Each teacher was free to participate or decline, knowing that participation ensured only a 50\% chance of receiving the intervention. Eighteen teachers elected to participate and were randomly assigned to either the intervention or the control group. A letter was sent to all English-speaking families requesting their child's participation in the assessment phase of the intervention. Approximately $70 \%$ of parents provided active consent for testing. Children were initially tested in either the prior spring or early fall of the intervention year; approximately $90 \%$ of the children were tested in the spring in order not to delay the onset of the intervention during the first few weeks of class. The children were then interviewed during the following spring, approximately 1 month postintervention. Follow-up testing was conducted each year in the spring in the following 3 years. At Time 1, children varied from first to second grade and at Time 4 from fourth to seventh grade.

\section{Data Analysis}

In the analysis reported on here, we evaluated whether the effects of PATHS were sustained in the follow-up years. We modeled the students' outcome trajectories across the early elementary grades using individual growth curve analysis, a form of multilevel modeling (Raudenbush \& Bryk, 1992; Rogosa, Brand, \& Zimowski, 1982; Rogosa \& Willet, 1985). Multilevel modeling is a recently developed statistical technique designed to deal with nesting data structures, such as the nesting of multiple observations within a person or the nesting of individuals in an organization. In longitudinal data, the model is at least a two-level hierarchical one. At Level 1, repeated observations of an individual are represented by a growth trajectory, the shape of which depends on a unique set of individual growth parameters. These parameters become the outcome variables in a Level-2 model, where they depend on some person-level characteristics. In our study, treatment status (intervention vs. control) was a predictor variable in the Level-2 model. In addition, each individual's growth parameters are allowed to vary randomly around the group (intervention and control) means. Multilevel models thus are also called random effects models.

In this study, models with random intercepts (at the 2-year follow-up), slopes, and curvature were fitted to the data via the computer program HLM 5.0 (Raudenbush, Bryk, Cheong, \& Congdon, 2000). Trajectories for students in the intervention group were compared to those of the students in the control group. Sustained intervention effects were indicated as positive changes in trajectories above and beyond those observed in the control group, as well as predicted treatment and control differences at the 2-year follow-up.

The statistical models fitted to all the longitudinal outcome data consisted of two-level random effects models (Raudenbush \& Bryk, 1992). Most of the models had a random intercept term that was "regressed" on the treatment status and a random slope term also "predicted" by treatment status. Raudenbush et al. (2000) used the following form:

$$
\begin{aligned}
& Y=B 0+B 1(\text { time })+r \\
& B 0=G 00+G 01(\text { Treatment })+U 0 \\
& B 1=G 10+G 11(\text { Treatment })+U 1
\end{aligned}
$$

In these equations, $Y$ is the outcome variable. $B 0$ and $B 1$ are the coefficients for the intercept (predicted outcome value at the last time of data collection for the outcome) and the slope (capturing the change in the outcome variable per unit time change). The effect of the PATHS on the mean level of the outcome at the specified follow-up time was estimated by $G 01$. The intervention effect on the rate of change is estimated by $G 11 . U 0$ and $U 1$ are the random components of the intercept and slope terms. Such a random effects model assumes that the children's outcome values and their rates of change vary randomly around the mean values of the group to which they belong. On the other hand, in the model fitted to the CDI data, the slope term $B 1$ did not have a random component (i.e., the $U 1$ term was dropped from the equation). In that case, it was a fixed effect, and all of the children in the same group had the same estimated slope.

As in most longitudinal studies, we had problems with attrition and missing data. The rate of missing data differed from outcome to outcome and also varied across years. Generally, larger attrition occurred in the follow-up years (CBCL-TRF: 15\%-46\%; TCRS: $14 \%-48 \%$; CDI: $28 \%$, no change; KAI: $6 \%-17 \%)$. For all of the children, we had baseline and postinter- 
vention data, and for many of them, more than 1 year of follow-up data. HLM 5.0 is a statistical procedure that uses full information maximum likelihood in its parameter estimation. In other words, in addition to a multilevel modeling procedure, it is also a missing data procedure (Collins, Schafer, \& Kam, 2001; Schafer \& Graham, 2002). Hence, under the "missing at random" assumption, maximum amount of information from the data is used to produce estimates that are unbiased and have a high efficiency.

\section{RESULTS}

As expected, compared to the general education students, the children in the special education classrooms exhibited higher baseline levels (measured at first grade) of externalizing and internalizing behaviors, higher levels of depression, and lower levels of emotional understanding and social problem-solving skills. Taking that into account, an intervention can be considered effective if it can either lower the level of problem behaviors or prevent it from increasing as well as raise the level of social-cognitive growth and social competence.

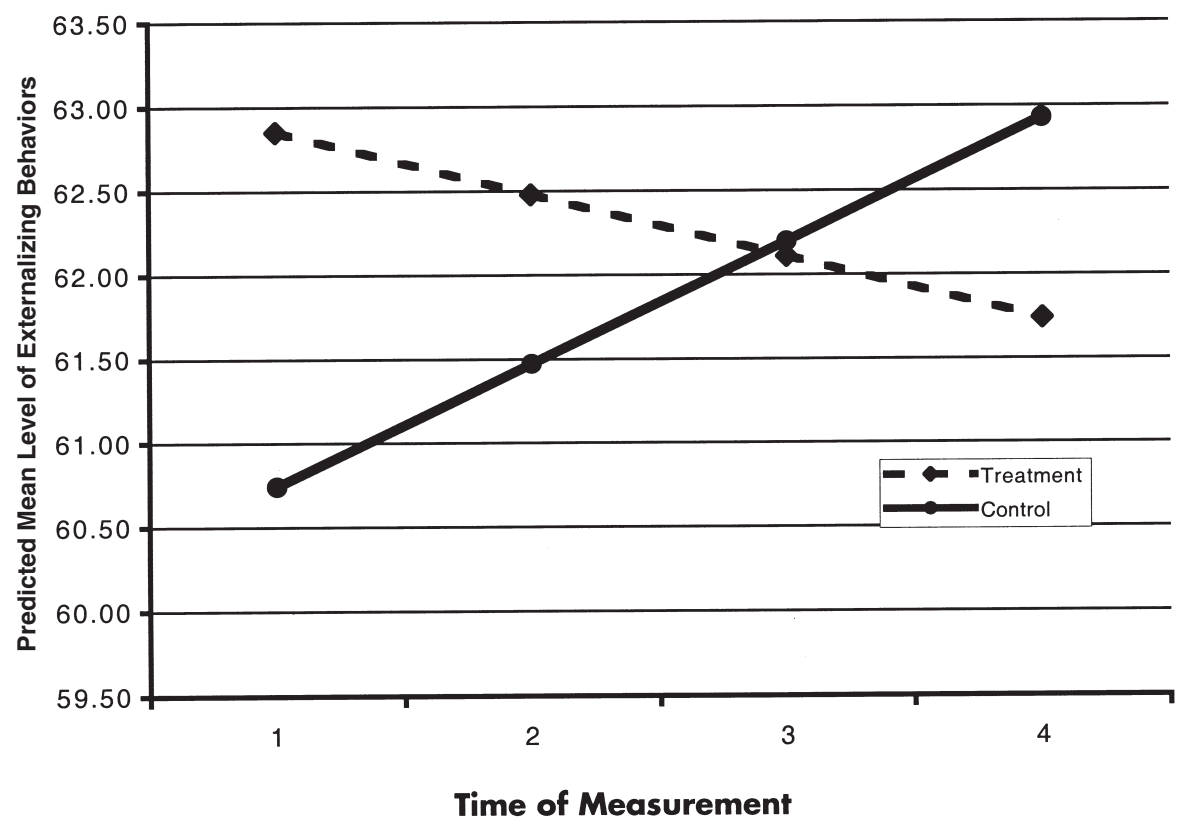

FIGURE I. Predicted trajectories of children's externalizing behaviors.

\section{Baseline Differences Between Groups}

Simple ANOVAs were performed to check for mean baseline differences between the treatment and control groups. No differences were found for the outcomes, except for internalizing behaviors. The treatment group had a significantly higher mean baseline internalizing behavior score; mean baseline treatment/ control difference $=4.8 ; F(1,84)=1.52$, $p=0.003$.

\section{Teacher-Rated Behaviors}

Trajectories of Externalizing Behaviors. A model with a linear trend fit relatively well with the externalizing behavior data, indicating that teachers' ratings of students' externalizing behaviors can best be described as changing linearly from Time 1 to Time 4. At the same time, significant random variations occurred in the rate of change among the students. A significant difference was found between the intervention and control groups in the estimated mean rate of growth in externalizing behaviors $(T$ ratio $=2.029, p<$ 0.05 ; Cohen's $d=0.18)$. On average, teachers' ratings of externalizing behav-

iors in the intervention group decreased at a rate of 0.37 points, whereas those in the control group increased at a rate of 0.72 points per year (see Figure 1). There was also a fair amount of variability in the estimated slope (random effect $S D=2.16$; $\left.\chi^{2}=203.64, p<0.0001\right)$.

Trajectories of Internalizing Behaviors. A linear growth model fit relatively well with the internalizing data. There was a significant intervention group difference in the rate of change of teachers' ratings of students' internalizing behaviors $(T$ ratio $=2.479, p<0.05$; Cohen's $d=$ $0.22)$. The ratings of the control group increased at the rate of 1.83 points per year, and ratings for the intervention group increased at the much lower rate- 0.38 points per year (see Figure 2). There was a fair amount of variability in the estimated slope (random effect $S D=1.84$; $\left.\chi^{2}=228.78, p<0.0001\right)$.

Social Competence. No significant intervention group differences were found for the trajectories of teacher-reported social competence. Specifically, there was no difference between the two groups in either the Year 3 follow-up levels or the rates of changes in teacher-rated frustration tolerance, assertive skills, task orientation, and peer sociability.

\section{Trajectories of Self-Reported Depression}

A linear growth curve model fit the CDI data relatively well. A significant difference between the two groups was found for the rate of decrease in the depression scores $(T$ ratio $=3.134, p<0.05$; Cohen's $d=0.49$ ). The depression scores reported by the students in the intervention group declined at a rate of 3.7 points per year, whereas the scores for the control group decreased at a rate of 0.85 . The estimated baseline depression for the treatment group was higher on average than for the control group (see Figure 3).

\section{Growth in Affective Vocabulary}

Linear trend models fit well with both positive and negative feelings vocabulary data. 
A significant difference between the two groups was found in the size of the negative feelings vocabulary at Time 4 $(T$ ratio $=2.832, p<0.05$; Cohen's $d=$ $0.54)$. In addition, there was "trend" treatment/control difference in the rate of increase in the negative feelings vocabulary $(T=1.617, p=0.11)$. The treatment group's rate of increase was 0.45 , whereas the control group's rate was 0.23 . There was no significant difference in the rate of change in the size of the positive feelings vocabulary.

\section{Social Problem-Solving Skills}

No significant intervention group difference was found in the growth curve analyses of efficacy in social problem solving among children in the special education classrooms. More specifically, there was no intervention versus control difference in the shape of the trajectories in the total number of effective solutions the children generated. Differences in the type of solutions that were generated were found, however. Children in the intervention condition displayed a marginally significant reduction in the percentage of aggressive solutions they generated (treatment: $22.5 \%$; control: $15.5 \% ; F=2.8, p<0.07$ ) and a significant increase in the percentage of solutions that were nonconfrontational and indicated self-control (treatment: $15 \%$; control: $8 \% ; F=3.4, p<0.0$ ).

\section{DISCUSSION}

For children who already show some signs of problem behaviors, a central goal of preventive intervention is to stop the emerging problem behaviors from escalating and becoming resistant to change. At the same time, protective factors, in terms of children's skills and cognitions as well as the quality of their classroom environment, must be strengthened to counteract the negative impact of risk factors.

Our results indicated that the PATHS curriculum is effective when it is implemented in special education environments. Its use had a significant impact in regards to teacher reports of externalizing and internalizing problems and substan-

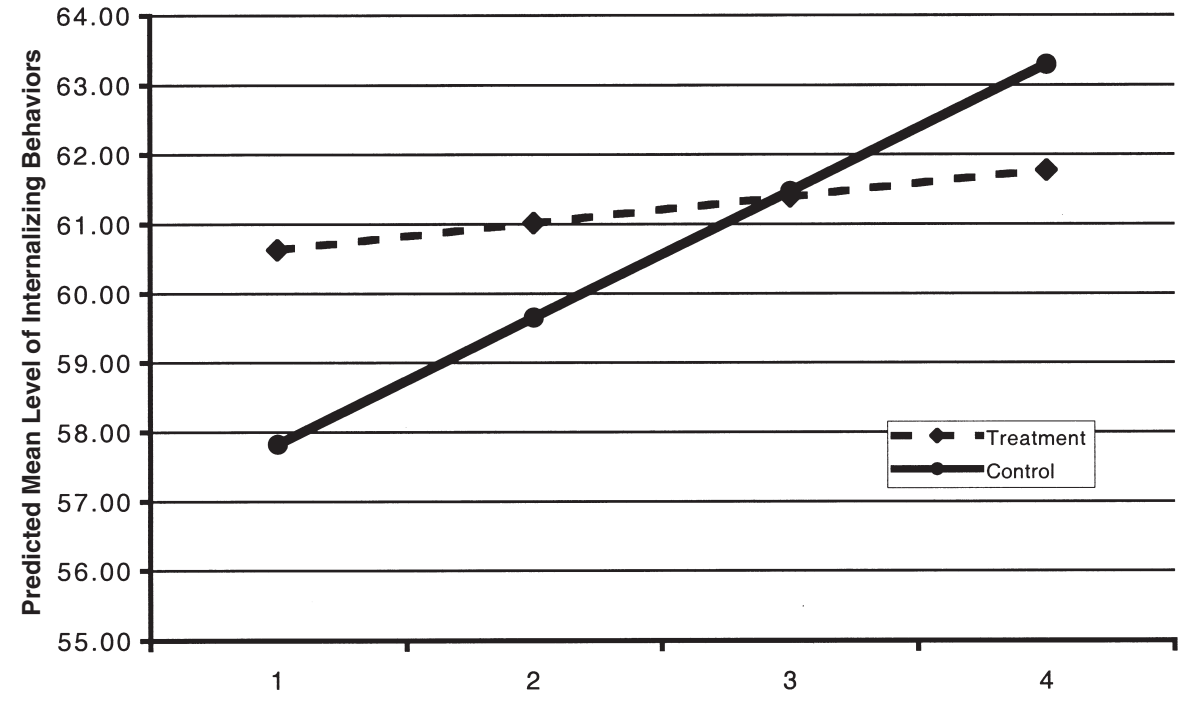

Time of Measurement

FIGURE 2. Predicted trajectories of children's internalizing behaviors.

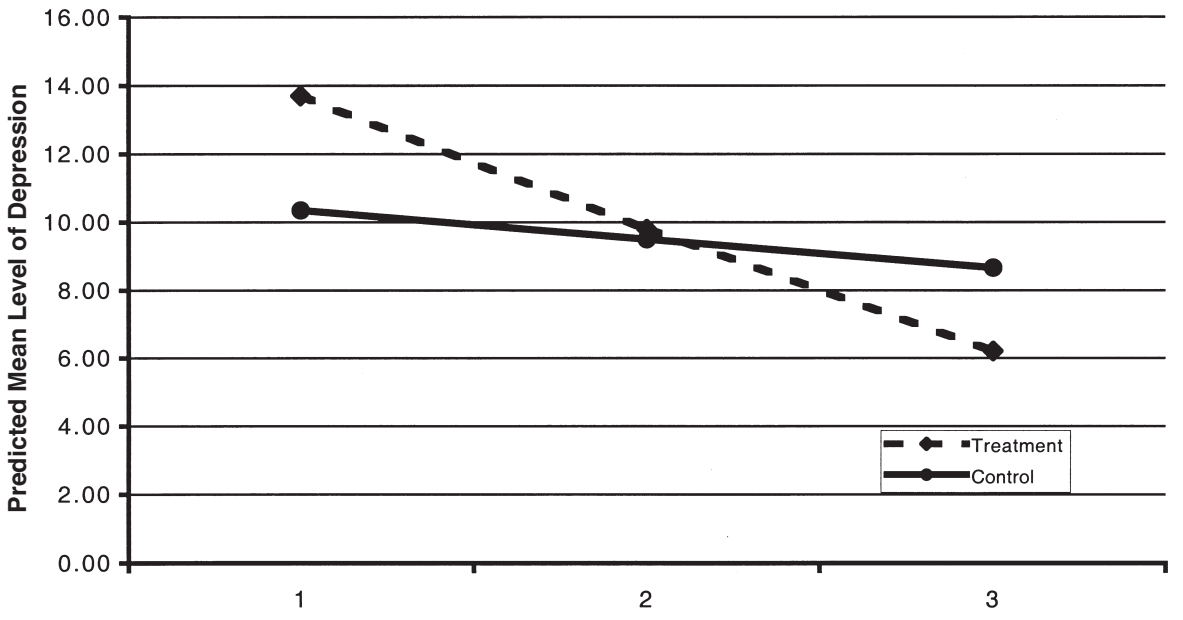

Time of Measurement

FIGURE 3. Predicted trajectories of children's self-reported depression.

tial reductions in self-reported depression in the children. Moreover, both the teachers and the children recognized these significant effects. The finding of cross-rater agreement is important because reports by the teacher or child alone may be subject to rater biases. Given the considerable comorbidity between externalizing and depressive symptoms in childhood, as well as the hypothesized brain processes involved with both, it is not surprising that acquiring skills in emotion regulation, self-control, and problem solving might affect both types of problems.

Furthermore, the growth curve analysis indicated that these effects were sustained 2 years after the intervention, a promising development. The trajectories for 
both externalizing and internalizing behaviors of the intervention group children continually decreased, while those for the control group children increased.

Congruent with the ABCD developmental model, the intervention led to significant, immediate improvements in the knowledge of both comfortable and uncomfortable feelings. (Further findings regarding the effects on the growth of emotional understanding in this population have been previously published [Greenberg et al., 1995].) At posttest, students who received PATHS displayed a greater fluency with understanding emotions and a greater ability to identify cues for recognizing feelings in others (see Greenberg et al., 1995, for more specific information on emotion-related knowledge outcomes). Results similarly indicated that the intervention group children were significantly more likely to provide solutions that were nonconfrontational and that demonstrated self-control; these findings fit well with the goals of teaching the turtle technique to help children stop and consider nonaggressive solutions to interpersonal dilemmas.

\section{Importance of Social- Emotional Learning}

We believe that a central reason for the significant findings with PATHS involves the use of an integrated paradigm that is grounded in a broad, interdisciplinary model of the developing child (Cicchetti \& Toth, 1998). The theoretical framework integrating affective, behavioral, cognitive, and linguistic development; our utilization of theoretical models from modern neuroscience and psychoanalytic thinking; and our conceptualization of the ecobehavioral interactions within the school all drive the actual activities used in the PATHS curriculum model (Greenberg, Kusché, \& Riggs, in press). Furthermore, both the current data and recent findings in neuroscience have pointed to the importance of considering social-emotional development as best understood within broader theories that take into account how children's experiences and relationships affect the children's brain organiza- tion, structuralization, and development (Fishbein, 2000; Luria, 1980).

\section{Special Education Issues and Preventive Intervention}

In their recent discussion of a new approach to prevention and treatment for children and youths with emotional and behavioral disorders (EBD), Farmer et al. (2001) suggested that a universal intervention may be the most effective strategy for helping children who are at moderate risk. Universal school-based interventions typically aim to build a supportive school climate for all students. If coordinated with other levels of prevention, they can be used to identify children early and to coordinate strategies for promoting competence and decreasing disability. These system-wide strategies are most suitable for dealing with what Farmer et al. (2001) called the "correlated constraints." According to Cairns, McGuire, and Gariepy (1993), different developmental factors-both internal and external to the individual-constrain each other and promote stability (i.e., continuity) in development. When several negative developmental factors work together to support problematic adjustment, it may be necessary to reorganize the entire system to revert the negative influences. Furthermore, for the effects of an intervention to "take hold," suppression of problem behaviors must be sustained for a reasonable time so that protective factors can be strengthened. In order to reduce risk, educators must take a long-term, comprehensive approach that focuses on building skills across the domains of emotion, cognition, and behavior (Greenberg, Weissberg, et al., 2003). It is likely that such approaches will show greater and more sustained effects, as compared to relatively brief social-skills training models that are relatively narrow in scope. The current findings fit with recent suggestions that special education consider the utility of new models of prevention (Forness et al., 2000; Kauffman, 1999a, 2000). PATHS is an example of a general model that can be tailored to indicated contexts (i.e., special needs classrooms) and universally applied in the entire school build- ing. Different modules of the model are differentially emphasized, with more focus in the special needs context on behavioral aspects of self-control and communication skills (Greenberg \& Kusché, 1993).

Although substantial positive intervention effects from the use of PATHS were found, the current study shed little light on the actual operation of PATHS within special education classrooms. It is a little puzzling that PATHS was able to reduce both teacher-rated behavior problems and selfreported depressive symptoms but failed to change the long-term trajectories of teacher-rated social competence.

There are a number of possible explanations. First, because of the need for a substantial emphasis on the basic skills of self-control and emotional understanding in special needs classrooms, this early version of PATHS did not have a sufficient focus on the acquisition of important social competencies. As a result of the findings reported here, the curriculum has been expanded to include lessons on friendship, the management of teasing and other difficult peer-related situations, and more behavioral practice and roleplaying. Second, given the limited amount of curricular time in the single-year model assessed in this study, teachers did not have the curricular time to cover the more advanced steps of social problem solving. Had the curriculum been extended to multiple years and provided a greater focus on interpersonal problem solving, it is possible that teachers' ratings of social competence might have been affected. A full test of the PATHS model should include a multiyear trial. A second reason may be that our teacher-rated measure of social competence was not sufficiently sensitive to changes. Clearly, improvements in measurement, including the use of observations of behavioral interactions with both peers and teachers, are necessary.

PATHS was not the only prevention/ intervention program that was implemented in the classrooms. By virtue of the nature of special education, specialized instructional programs and individualized education programs were being implemented along with PATHS, as well as in the control group classrooms. It there- 
fore is important to realize that this study compared PATHS and specialized programs in the treatment group to specialized programs alone in the control classrooms. From a practice standpoint, it would be quite useful to use ethnographic/ qualitative methods to further understand how the teaching of PATHS is integrated with existing programs in the special education classrooms. In this regard, PATHS is intended to not only build skills in students but also improve the teacherstudent relationship and classroom climate. Although such effects were found in another trial of PATHS in general education classrooms (Conduct Problems Prevention Research Group, 1999), we did not assess whether this ecological change occurred in the special needs classrooms. In addition, given the heavy preservice training emphasis on both individualization and behavioral training in special education, it would be useful to contrast approaches to implementation and the frequency of use of generalization strategies by special education teachers as compared to general education teachers.

In the current study, most of the children were educated in self-contained classrooms for most or all of the school day. The various disability statuses were asigned a variety of state-designated classifications, however, including emotional disturbance, mild mental delay, learning disabilities, and health impairments. As indicated by the high average scores on externalizing behavior problems, most students with learning problems had associated behavioral difficulties that led to their placement in primarily selfcontained classroom settings. Unfortunately, analyses by classification were not possible in this study due to the relatively small sample size of each subclass. A central question for future research thus would concern the differences in response to the intervention by students with different characteristics and in different classifications.

\section{Conclusions}

The present study examined the effects of the PATHS curriculum in the context of special needs classrooms and indicated a substantial impact on the reduction of psychopathology. It did not involve a comprehensive initiative in which PATHS was also used in all general education classrooms. A greater impact probably would have been seen if we had used a comprehensive model that included all classrooms and involved the use of generalization strategies (Turtle Technique, visible Control Signals Posters, etc.) in the hallways, lunchroom, playground, and buses. A central research area would be to examine the effectiveness of preventive interventions (such as PATHS) using a comprehensive classroom-wide/school-wide intervention approach that would focus on cross-setting generalization and have greater ecological validity (discussed in Evans, Axelrod, \& Sapia, 2000; Sheridan, Hungelmann, \& Maughan, 1999).

\section{About the Authors}

CHI-MING KAM, PhD, is an assistant professor of psychology at City College of New York. His current interests include preventive interventions for school-age children, the social and emotional development of children with special needs, and research methodology in longitudinal and prevention studies. MARK T. GREENBERG, PhD, is director of The Prevention Center for the Promotion of Human Development at Pennsylvania State University. His research focuses on the social, emotional, and cognitive factors that influence well-being and psychopathology in childhood and adolescence. CAROL A. KUSCHE, PhD, is a clinical assistant professor in the Department of Psychology at the University of Washington. She is a psychoanalyst and clinical psychologist in private practice. Her research interests concern the emotional development of children and the development of schoolbased preventive interventions to promote well-being. Address: Mark T. Greenberg, Prevention Research Center, Pennsylvania State University, Henderson South 112, University Park, PA 16802; e-mail: mxg47@psu.edu

\section{Authors' Notes}

1. This research was supported by Grant PHS RO1 MH42131 from the Prevention Branch of the National Institute of Mental Health.

2. The authors thank Lisa Anderson and Dawn Kresevich for their invaluable help with data collection, Bob Beilke for his assistance in the development of the KAI-R coding system, and the dedicated coders of the KAI-R for their careful work.

\section{References}

Achenbach, T. M. (1991). Manual for the Teacher's Report Form and 1991 profile. Burlington: University of Vermont, Department of Psychiatry.

Bender, W. N., \& Wall, M. E. (1994). Socialemotional development of students with learning disabilities. Learning Disability Quarterly, 17, 323-341.

Bender, W. N., Rosenkrans, C. B., \& Crane, M. K. (1999). Stress, depression, and suicide among students with learning disabilities: Assessing the risk. Learning Disability Quarterly, 22, 143-156.

Bryan, T. (1991). Assessment of social cognition: Review of research in learning disabilities. In H. L. Swanson (Ed.), Handbook on the assessment of learning disabilities: Theory, research and practice (pp. 285311). Austin, TX: PRO-ED.

Bryan, T. (1997). Assessing the personal and social status of students with learning disabilities. Learning Disabilities Research and Practice, 12(1), 63-76.

Cairns, R. B., McGuire, A. M., \& Gariepy, J. L. (1993). Developmental behavior genetics: Fusion, correlated constraints, and timing. In D. F. Hay \& A. Angold (Eds.), Precursors and causes in development and psychopathology (pp. 87-122). New York: Wiley.

Carnine, D. (1997). Bridging the researchto-practice gap. Exceptional Children, 63, 513-523.

Chapman, J. W. (1988). Learning disabled children's self-concepts. Review of Educational Research, 58, 347-371.

Cheney, D., Greenberg, M. T., \& Kusché, C. A. (1991). Teacher effectiveness with PATHS: A social-cognitive curriculum for elementary students. In J. Tindal \& J., Marr (Eds.), The Oregon Conference monograph 1991. Eugene: University of Oregon, College of Education.

Cicchetti, D., \& Toth, S. L. (1998). Perspectives on research and practice in developmental psychopathology. In W. Damon (Series Ed.), I. Sigel, \& K. A. Renninger (Vol. Eds.), Handbook of child psychology: Vol.4. Child psychology in practice (5th ed., pp. 479-583). New York: Wiley.

Collins, L. M., Schafer, J. L., \& Kam, C. (2001). A comparison of inclusive and restrictive strategies in modern missing 
data procedures. Psychological Methods, 6, 317-329.

Conduct Problems Prevention Research Group. (1999). Initial impact of the Fast Track prevention trial for conduct problems: II. Classroom effects. Journal of Consulting and Clinical Psychology, 67, 648-657.

Dewey, J. (1933). How we think. Boston: D. C. Heath.

Dodge, K. A. (1986). A social information processing model of social competence in children. In M. Perlmutter (Ed.), Cognitive perspectives on children's social behavior and behavioral development: The Minnesota Symposium on Child Psychology (Vol. 18). Hillsdale, NJ: Erlbaum.

Dudley-Marling, C. C., \& Edmiaston, R. (1985). Social status of learning disabled children and adolescents: A review. Learning Disability Quarterly, 8, 189-204.

Durlak, J. A. (1995). School-based prevention programs for children and adolescents. Thousand Oaks, CA: Sage.

Durlak, J. A., \& Wells, A. M. (1997). Primary prevention mental health programs for children and adolescents: A meta-analytic review. American Journal of Community Psychology, 25, 115-152.

D'Zurilla, T. J., \& Goldfried, M. R. (1971). Problem solving and behavior modification. Journal of Abnormal Psychology, 78, 107126.

Elias, M. J., \& Clabby, J. (1989). Building social problem solving skills: Guidelines from a school-based program. San Francisco: Jossey-Bass.

Evans, S. W., Axelrod, J. L., \& Sapia, J. L. (2000). Effective school-based mental health interventions: Advancing the social skills training paradigm. Journal of School Health, 70(5), 191-194.

Farmer, T. W. (2000). Misconceptions of peer rejection and problem behavior: Understanding aggression in students with mild disabilities. Remedial and Special Education, 21, 194-208.

Farmer, T. W., \& Hollowell, J. H. (1994). Social networks in mainstream classrooms: Social affiliations and behavioral characteristics of students with emotional and behavioral disorders. Journal of Emotional and Behavioral Disorders, 2, 143-155, 163.

Farmer, T. W., Quinn, M. M., Hussey, W., \& Holahan, T. (2001). The development of disruptive behavioral disorders and correlated constraints: Implications for intervention. Behavioral Disorders, 26, 117-130.

Fishbein, D. H. (2000). The importance of neurobiological research to the prevention of psychopathology. Prevention Science, 1(2), 89-106.

Forness, S. R., Serna, L. A., Nielsen, E., Lambros, K., Hale, M. J., \& Kavale, L. A. (2000). A model for early detection and primary prevention of emotional or behavioral disorders. Education and Treatment of Children, 23, 325-345.

Gallico, R., Burns, T., \& Grob, C. (1988).Emotional and behavioral problems in children with learning disabilities. Boston: CollegeHill Press.

Gordon, S. L. (1989). The socialization of children's emotions: Emotional culture, competence and exposure. In C. Saarni \& P. L. Harris (Eds.), Children's understanding of emotion. New York: Cambridge University Press.

Grande, C. G. (1988). Delinquency: The learning disabled student's reaction to academic school failure. Adolescence, 23, 209-218.

Greenberg, M. T., Domitrovich, C., \& Bumbarger, B. (2001). The prevention of mental disorders in school-aged children: Current state of the field. Prevention and Treatment, 4 (Article 1). Retrieved November 10, 2002, from http://journals.apa.org/ prevention/volume4/pre004001a.html

Greenberg, M. T., Kam, C., Henirichs, B., \& Conduct Problems Prevention Research Group. (2003, June). The cumulative effects of the PATHS curriculum: Outcomes at Grade 3. Paper presented at annual meeting of the Society for Prevention Research, Washington, DC.

Greenberg, M. T., \& Kusché, C. A. (1988). The social problem-solving interview. Unpublished manuscript, University of Washington, Seattle.

Greenberg, M. T., \& Kusché, C. A. (1993). Promoting social and emotional development in deaf children: The PATHS Project. Seattle: University of Washington Press.

Greenberg, M. T., Kusché, C. A., Cook, E. T., \& Quamma, J. P. (1995). Promoting emotional competence in school-aged children: The effects of the PATHS curriculum. Development and Psychopathology, 7, 117136.

Greenberg, M. T., Kusché, C. A., \& Riggs, N. (in press). The PATHS curriculum: Theory and research on neuro-cognitive development and school success. In J. Zins, R. Weissberg, \& H. Walberg (Eds.), Building school success on social and emotional learning. New York: Teachers College Press. Greenberg, M. T., Kusché, C. A., \& Speltz, M. (1990). Emotional regulation, self-control and psychopathology: The role of relation- ships in early childhood. In D. Cicchetti \& S. Toth (Eds.), Rochester symposium on developmental psychopathology (Vol. 2, pp. 21-56). New York: Cambridge University Press.

Greenberg, M. T., Weissberg, R. P., Utne O'Brien, M., Zins, J. E., Fredericks, L., Resnik, H., et al. (2003). Enhancing schoolbased prevention and youth development through coordinated social, emotional, and academic learning. American Psychologist, 58, 466-474.

Hightower, A. D., Work, W. C., Cowen, E. L., Lotyczewski, B. S., Spinell, A. P., Guare, J. C., et al. (1986). The Teacher-Child Rating Scale: A brief objective measure of elementary children's school problem behaviors and compentencies. School Psychology Review, 15, 393-409.

Hindley, P., \& Reed, R. (1999). Promoting alternative thinking strategies (PATHS): Mental health promotion with deaf children in school. In S. Decker, S. Kirby, A. Greenwood, \& D. Moores (Eds.), Taking children seriously (pp. 68-87). London: Cassell.

Huntington, D. D., \& Bender, W. N. (1993). Adolescents with learning disabilities at risk? Emotional well being, depression, suicide. Journal of Learning Disabilities, 26, 159-166.

Institute of Medicine. (1994). Reducing risks for mental disorders: Frontiers for preventive intervention research. Washington, DC: National Academy of Sciences Press.

Kamps, D., Kravits, T., Stolze, J., \& Swaggart, B. (1999). Prevention strategies for at-risk students and students with EBD in urban elementary schools. Journal of Emotional and Behavioral Disorders, 7, 178-188.

Katan,A. (1961). Some thoughts about the role of verbalization in early childhood. Psychoanalytic Study of the Child, 16, 184-188.

Kauffman, J. M. (1999a). How we prevent the prevention of emotional and behavioral disorders. Exceptional Children, 65, 448-468.

Kauffman, J. M. (1999b). Today's special education and its messages for tomorrow. The Journal of Special Education, 32, 244-254.

Kauffman, J. M. (2000). Future directions with troubled children. Reclaiming Children and Youth, 9, 119-124.

Kavale, K. A., \& Forness, S. R. (1996). Social skill deficits and learning disabilities: A meta-analysis. Journal of Learning Disabilities, 29, 226-237.

Keilitz, I., \& Dunivant, N. (1987). The learning disabled offender. In C. M. Nelson, R. B. Rutherford, \& B. I. Wolford (Eds.), Special education in the criminal justice 
system (pp. 120-137). Colombus, OH: Merrill.

Kendall, P. C., \& Braswell,L. (1985). Cognitivebehavioral therapy for impulsive children. New York: Guilford Press.

Kendler, T. S. (1963). Development of mediating responses in children. In J. C. Wright \& J. Kagan (Eds.), Basic cognitive processes in children: Monographs of the Society for Research in Child Development, 28(2, Serial No. 86, pp. 33-51). Boston: Blackwell.

Kopp, C. (1982). The antecedents of selfregulation. Developmental Psychology, 18, 199-214.

Kovacs, M. (1983). The Children's Depression Inventory: A self-rated depression scale for school-aged youngsters. Unpublished manuscript, University of Pittsburgh School of Medicine.

Kovacs, M. (1992). Children's depression inventory. New York: Multi-Health Systems.

Kratochwill, T. R., \& Stoiber, K. C. (2000). Empirically supported interventions and school psychology: Conceptual and practice issues. School Psychology Quarterly, 15, 233-253.

Kusché, C. A., \& Greenberg, M. T. (1994). The PATHS curriculum. Seattle: Developmental Research and Programs.

Kusché, C. A., Greenberg, M. T., \& Beilke, B. (1988). The Kusché affective interview. Unpublished manuscript, University of Washington, Department of Psychology.

La Greca, A. M, \& Vaughn, S. (1992). Social functioning of individuals with learning disabilities. School Psychology Review, 21, 340-347.

Landau, S., \& Moore, L. (1991). Social skill deficit in children with attention-deficit hyperactivity disorder. School Psychology Review, 20, 235-251.

Luria, A. R. (1980). Higher cortical functions in man. New York: Basic Books.

Malatesta, C. Z. (1990). The role of emotions in the development and organization of personality. In R. A. Thompson (Ed.), Socioemotional development: Nebraska Symposium on Motivation (Vol. 36). Lincoln: University of Nebraska Press.

Meichenbaum, D. (1977). Cognitive-behavior modification: An integrative approach. New York: Plenum Press.

McBride, H. E. A., \& Seigel, L. S. (1997). Learning disabilities and adolescent suicide. Journal of Learning Disabilities, 30 , 652-659.

Myers, P., \& Hammill, D. D. (1990). Learning disabilities: Basic concepts, assessment practices and instructional strategies (4th ed.) Austin, TX: PRO-ED.

Payton, J. W., Wardlaw, D. M., Gracyzk, P. A., Bloodworth, M. R., Tompsett, C. J., \& Weissberg, R. P. (2000). Social and emotional learning: A framework for promoting mental health and reducing risk behaviors in children and youth. Journal of School Health, 70(5), 179-185.

Pearl, R. (1987). Social cognitive factors in learning-disabled children's social problems. In S. J. Ceci (Ed.), Handbook of cognitive, social and neuropsychological aspects of learning disabilities (pp. 273-294). Hillsdale, NJ: Erlbaum.

Pearl, R. (1992). Psychosocial characteristics of learning disabled students. In N. N. Singh \& I. L. Beale (Eds.), Learning disabilities: Nature, theory, and treatment (pp. 96-125). San Diego, CA: Academic Press.

Pellegrini, D. S., \& Urbain, E. S. (1985). An evaluation of interpersonal cognitive problem solving training with children. Journal of Child Psychology and Psychiatry, 26 (1), 17-41.

Pine, F. (1985). Developmental theory and clinical process. New Haven, CT: Yale University Press.

Raudenbush, S. W., \& Bryk, A. S. (1992). Hierarchical linear models: Applications and data analysis methods. Newbury Park, CA: Sage.

Raudenbush, S. W., Bryk, A. S., Cheong, Y. F., \& Congdon, R. T. (2000). HLM 5: Hierarchical linear and nonlinear modeling. Lincolnwood, IL: Scientific Software International.

Rogosa, D. R., Brand, D., \& Zimowski, M. (1982). A growth curve approach to the measurement of change. Psychological Bulletin, 90, 726-748.

Rogosa, D. R. \& Willet, J. B. (1985). Understanding correlates of change by modeling individual differences in growth. Psychometrika, 50, 203-228.

Saarni, C., \& Harris, P. L. (Eds.). (1989). Children's understanding of emotion. New York: Cambridge University Press.

Schafer, J. L., \& Graham, J. W. (2002). Missing data: Our view of the state of the art. Psychological Methods, 7(2), 147-177.

Schneider, M., \& Robin, A. (1978). Manual for the turtle technique. Unpublished manuscript, State University of New York at Stony Brook, Department of Psychology.

Schumaker, J. B., \& Hazel, J. S. (1988). Social skills and learning disabilities: Current issues and recommendations for future research. In J. F. Kavanagh \& T. T. Truss
(Eds.), Learning disabilities: Proceedings of the national conference (pp. 293-344). Parkton, MD: York Press.

Sheridan, S., Hungelmann, A., \& Maughan, D. P. (1999). A contextualized framework for social skills assessment, intervention and generalization. School Psychology Review, 28, 84-103.

Shure, M. B., \& Spivak, G. (1978). Problemsolving techniques in childrearing. San Francisco: Jossey-Bass.

Shure, M. B., \& Spivak, G. (1988). Interpersonal cognitive problem solving. In R. H. Price, E. L. Cowen, R. P. Lorion, \& J. Ramos-McKay (Eds.), Fourteen ounces of prevention: A casebook for practitioners (pp. 69-82). Washington, DC: American Psychological Association.

Simpson, R. L. (1999). Children and youth with emotional and behavioral disorders: A concerned look at the present and a hopeful eye for the future. Behavioral Disorders, 24, 284-292.

Spivak, G., \& Shure, M. (1974). Social adjustment of young children: A cognitive approach to solving real-life problems. San Francisco: Jossey-Bass.

Stoiber, K. C., \& Kratochwill, T. R. (2000). Empirically supported interventions and school psychology: Rationale and methodological issues-Part I. School Psychology Quarterly, 15, 75-105.

Urbain, E. S., \& Savage, P. (1989). Interpersonal cognitive problem-solving training with children in the schools. In J. N. Hughes \& R. J. Hall (Eds.), Cognitive-behavioral psychology in the schools: A comprehensive handbook. New York: Guilford Press.

Vygostsky, L. S. (1978). Mind in society. Cambridge, MA: Harvard University Press.

Walker, H. M., Kavanagh, K., Stiller, B., Golly, A., Severson, H. H., \& Geil, E. G. (1998). First step to success: An early intervention approach for preventing school antisocial behavior. Journal of Emotional and Behavioral Disorders, 6, 66-80.

Weissberg, R. P., Caplan, M. Z., \& Bennetto, L. (1988). The Yale-New Haven middleschool social problem solving (SPS) program. New Haven, CT: Yale University.

Weissberg, R. P., \& Elias, M. J. (1993). Enhancing young people's social competence and health behavior: An important challenge for educators, scientists, policymakers, and funders. Applied and Preventive Psychology, 2, 179-190.

Weissberg, R. P., Gesten, E. L., Rapkin, B. D., Cowen, E. L., Davidson, E., de Apodaca, R. F., et al. (1981). Evaluation of a social- 
problem-solving training program for suburban and inner-city third-grade children. Journal of Consulting and Clinical Psychology, 49, 251-261.

Weissberg, R. P., \& Greenberg, M. T. (1998). Social and community competence- enhancement and prevention programs. In W. Damon (Ed.), Handbook of child psychology: Vol. 4. Child psychology in practice (5th ed., pp. 877-954). New York: Wiley.
White, S. H. (1965). Evidence for a hierarchical arrangement of learning processes. In L. P. Lipsett \& C. C. Spider (Eds.), Advances in child development and behavior (Vol. 2, pp. 103-142). New York: Academic Press.

\section{;:pro.ed \\ Journal of Emotional and Behavioral Disorders}

Your subscription to JEBD includes online access!

\section{Benefits include:}

- e-journal access 24 hours a day, 7 days a week, 365 days a year

- Document-to-document linking via references for fast, reliable access to the wider literature

- Fully searchable across full text, abstracts, titles, tables of contents, and figures

- Links to and from major abstract and indexing resources to aid research

- Full-text searching across multiple journals

- TOC alerting service
Set up access now! Go to:

www.proedinc.com/journals-online.html

... and follow the online instructions.

Questions? Contact:

journals@proedinc.com

Need more help? Free tech support: support@ingenta.com

\section{Not a subscriber? Contact www.proedinc.com today!}

PRO-ED, Inc. • 8700 Shoal Creek Blvd. • Austin, Texas 78757-6897

ph $800 / 897-3202$ or $512 / 451-3246$ • fax $800 / F X P R O E D$

www.proedinc.com 
Copyright of Journal of Emotional \& Behavioral Disorders is the property of PRO-ED and its content may not be copied or emailed to multiple sites or posted to a listserv without the copyright holder's express written permission. However, users may print, download, or email articles for individual use. 